
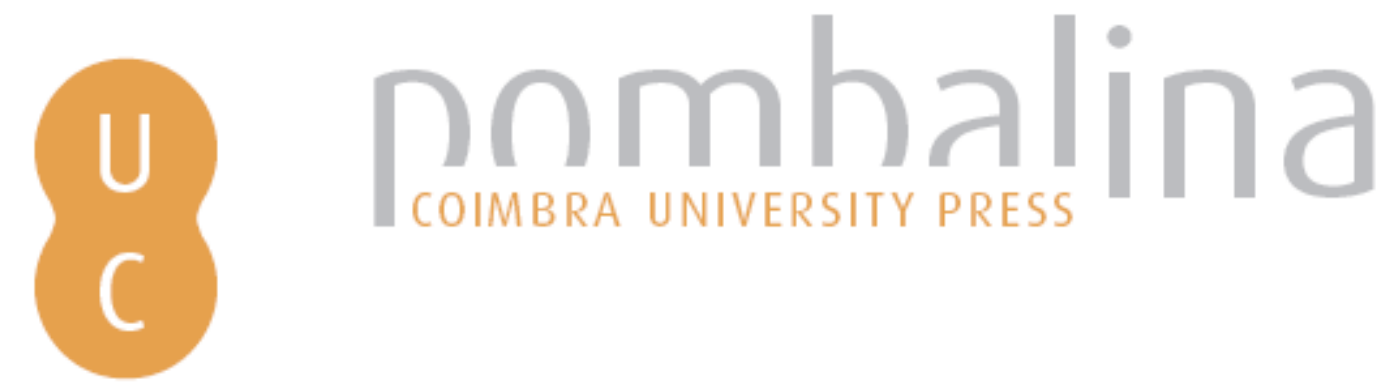

\title{
Anticipating the severity of the fire season in Northern Portugal using statistical models based on meteorological indices of fire danger
}

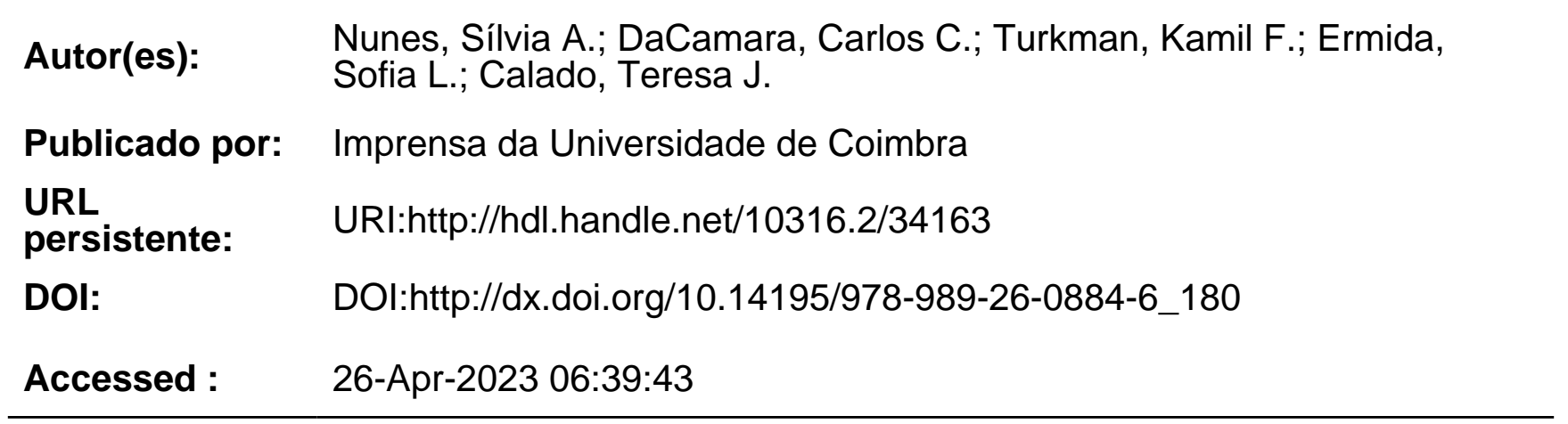

A navegação consulta e descarregamento dos títulos inseridos nas Bibliotecas Digitais UC Digitalis, UC Pombalina e UC Impactum, pressupõem a aceitação plena e sem reservas dos Termos e Condições de Uso destas Bibliotecas Digitais, disponíveis em https://digitalis.uc.pt/pt-pt/termos.

Conforme exposto nos referidos Termos e Condições de Uso, o descarregamento de títulos de acesso restrito requer uma licença válida de autorização devendo o utilizador aceder ao(s) documento(s) a partir de um endereço de IP da instituição detentora da supramencionada licença.

Ao utilizador é apenas permitido o descarregamento para uso pessoal, pelo que o emprego do(s) título(s) descarregado(s) para outro fim, designadamente comercial, carece de autorização do respetivo autor ou editor da obra.

Na medida em que todas as obras da UC Digitalis se encontram protegidas pelo Código do Direito de Autor e Direitos Conexos e demais legislação aplicável, toda a cópia, parcial ou total, deste documento, nos casos em que é legalmente admitida, deverá conter ou fazer-se acompanhar por este aviso.

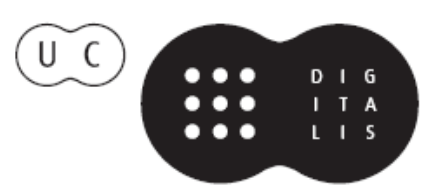




\section{ADVANCES IN}

Forest Fire

\section{RESEARCH}

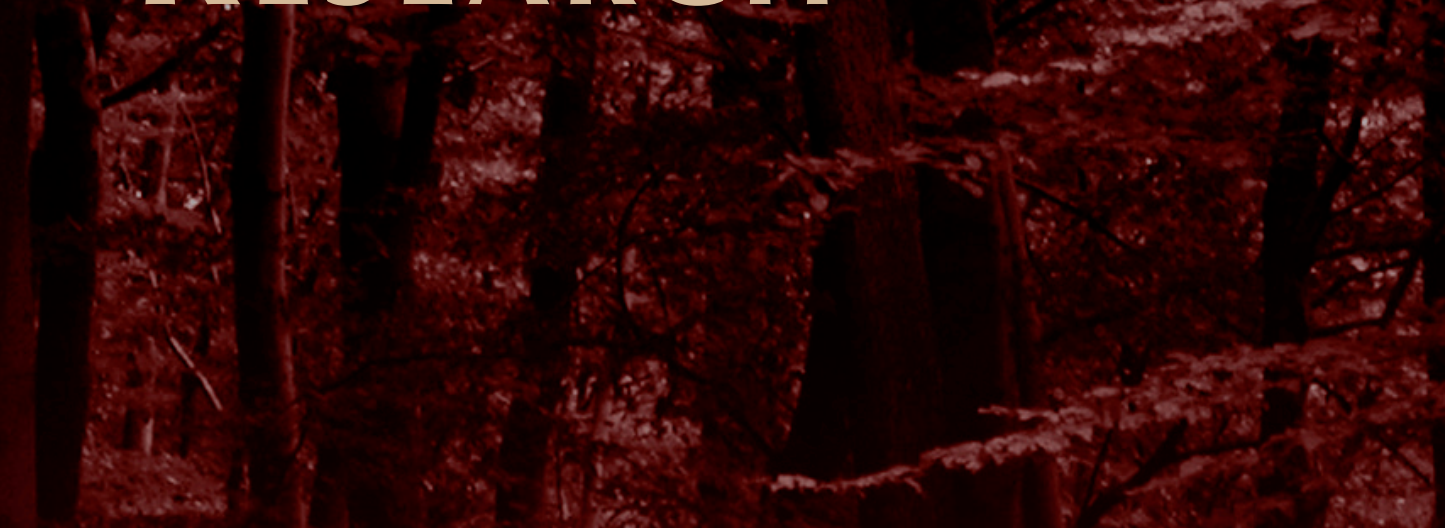

\section{DOMINGOS XAVIER VIEGAS}

\section{EDITOR}




\title{
Anticipating the severity of the fire season in Northern Portugal using statistical models based on meteorological indices of fire danger
}

\author{
Sílvia A. Nunes ${ }^{\mathrm{a}}$, Carlos C. DaCamara ${ }^{\mathrm{a}}$, Kamil F. Turkman ${ }^{\mathrm{b}}$, Sofia L. Ermida ${ }^{\mathrm{a}}$, and Teresa J. Calado ${ }^{\mathrm{a}}$ \\ ${ }^{a}$ Instituto Dom Luiz, Faculdade de Ciências, Universidade de Lisboa, 1749-016 Lisboa, Portugal, \\ sanunes@fc.ul.pt, cdcamara@fc.ul.pt, snermida@fc.ul.pt, mtcalado@fc.ul.pt \\ ${ }^{b}$ DEIO-CEAUL, Universidade de Lisboa, 1749-016 Lisboa, Portugal, kfturkman@fc.ul.pt
}

\begin{abstract}
Climate and weather are major drivers of fire activity in Portugal. The aim of the present study is to assess the role of meteorological factors on the inter-annual variability of burned area, for the period 1980-2011, over a region of Central Portugal. Although occupying only $18 \%$ of the territory of Portugal, the chosen area is responsible for $43 \%$ of all the burned area in August during the study period.

A normal distribution model is fitted to the decimal logarithms of monthly burned area during August over the study area. This model is then improved by introducing as covariates two different measures of prevailing meteorological conditions as derived from Daily Severity Rate (DSR), namely a top-down factor which consists of daily cumulated values of DSR from April up to July and a bottom-up factor defined as the square root of the mean of the squared daily positive deviations of DSR in August from the daily climatology. The two models are used to derive a model of fire severity that allows quantifying the probability of having a severe or weak fire season.
\end{abstract}

Keywords: fire activity, burned area, indices of fire danger, meteorological conditions, statistical models

\section{Introduction}

The number and extension of fires and the large amounts of burned area that are observed in Mediterranean Europe have strong adverse impacts at the social, economic, ecological and environmental levels that include the destruction and change of the landscape and the emission of greenhouse gases (Pausas and Vallejo, 1999). The increase in temperature that is to be expected according to future climate scenarios may also turn more frequent fire episodes of large magnitude (Flannigan et al., 2013; Liu et al., 2010; Mori and Johnson, 2013; Yongqiang et al., 2010). It is therefore crucial to improve our knowledge about fire behaviour (especially about extreme fire events), that will help taking adequate measures to mitigate the adverse effects.

The Mediterranean region is responsible for $85 \%$ of burned area in Europe, causing extensive economic losses and ecological damages (San-Miguel-Ayanaz et al., 2013). In particular, Portugal presents the highest score of fire occurrences in the Mediterranean Basin (Pereira et al., 2005). According to official records of Instituto de Conservação da Natureza e das Florestas (ICNF), the Portuguese authority for forests, 3,468,986 hectares have burned in Continental Portugal during the period 1980-2011, the equivalent to three fifths of the total forested area of the country; in the last few years, a significant increase has also been observed in the amount of total burned area, number of large fires and fire severity (Pereira et al., 2011).

Fire activity in Mediterranean Europe, is a natural phenomenon linking climate, humans and vegetation (Lavorel et al., 2007). Fire activity is therefore conditioned by natural and anthropogenic factors (San-Miguel-Ayanz et al., 2003). According to Costa et al. (2011) and Ganteaume et al. (2013) the most important factors for fire occurrence in Mediterranean Europe are anthropogenic and environmental. The first one is the main cause of ignition, reaching 95\% of all cases (San-MiguelAyanz et al., 2013) whereas the most significant environmental factors are weather, fuel availability and topography. Even though most of fire events are human caused, several studies show that climate 
and associated weather conditions are major drivers for fires with extensive burned area. For instance, rainy and mild winters followed by warm and dry summers lead to high levels of vegetation stress making the region particularly prone to the occurrence of fire events (Pereira et al., 2005); while precipitation and temperature in the pre-fire season have a determinant role in fuel availability and vegetation stress, temperature, wind and precipitation in the fire season are crucial for the development and extinction stages (Aldersley et al., 2011; Dale et al., 2001; Pereira et al., 2013; Trigo et al., 2013). The aim of the present study is to contribute to a better understanding of the meteorological factors that affect the inter-annual variability of burned area in August over a region in Central Portugal. Meteorological information is used to derive the so-called Daily Severity Rate (DSR), an index of fire danger that is part of the Canadian Forest Fire Weather Index System (CFFWIS). This index is then used to characterize the pre-fire season in terms of levels of heat and stress of vegetation, as well as an indicator of extreme meteorological conditions taking place in summer. A normal distribution model is fitted to the decimal logarithms of monthly burned area during August over the study area. This model is then improved by introducing as covariates two different measures of prevailing meteorological conditions as derived from the Daily Severity Rate (DSR); a top-down factor, DSR td $_{\text {, }}$ which consists of daily cumulated values of DSR from April up to July and a bottom-up factor, DSR bu $_{\text {, }}$ defined as the square root of the mean of the squared daily positive deviations of DSR in August from the daily climatology. A model of fire severity is finally derived that allows quantifying the probability of having a severe or weak fire season.

\section{Data and methods}

\subsection{Study area and period}

The study area is located in Central Portugal (Figure 1) and encompasses 53 counties (concelhos). The study area covers 1,805,226 ha, 30\% of which are covered by forest. The two main species in the forested area are Pinus Pinaster (58\%) and Eucalyptus (22\%). The high percentage values of maritime pine and eucalyptus, that are extremely flammable in summer (Núñez-Regueira et al., 1996), can explain the fact that although the study area occupies only $18 \%$ of all the territory of Portugal it is responsible for $43 \%$ of the total burned area in August during the study period (Figure 2).
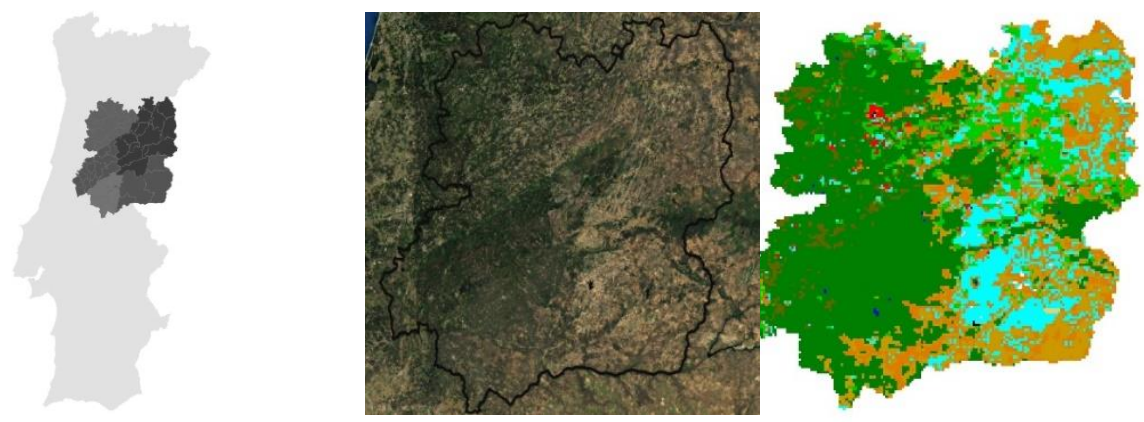

Figure 1. Location of the study area (left panel), RGB zoom image of the area from ArcGlobe 10 (middle panel) and GLC2000 map (right panel) identifying forest (green), cultivated and managed areas (cyan), shrubland (orange) and bare soils and sparse vegetation (red).

The study covers the 32-year period 1980-2011, and focuses on yearly amounts of cumulated burned area $(B A)$ in August over the study area. As shown in Figure 2, the time series of $B A$ presents a very large inter-annual variability and is highly correlated $(\mathrm{r}=0.93)$ with the time series of Continental Portugal. 


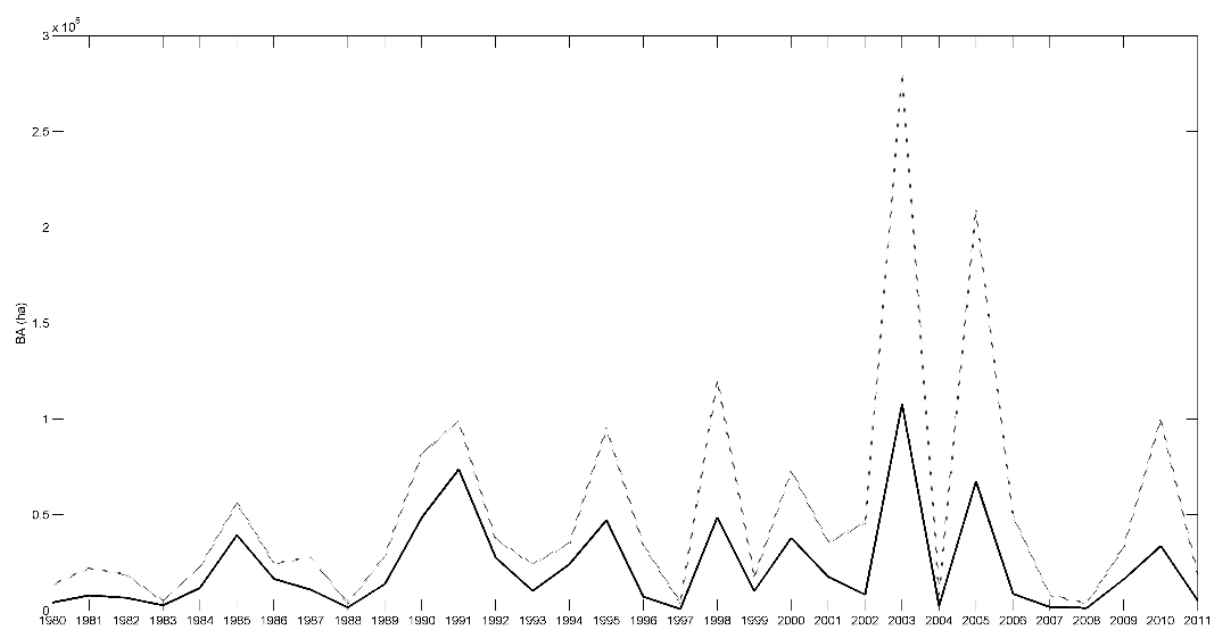

Figure 2. Time series of cumulated burned area in August over the study area (black curve) and over Continental Portugal (dotted curve)

\subsection{Fire database}

Values of burned area in Portugal are derived from the official Portuguese Rural Fire Database (PRFD) provided by ICNF. The database covers a 32-year period (1980-2011) and includes more than half a million records of fire events over forest, shrubland, grassland and agricultural land. It includes the data and time of ignition and extinction, total burned area, cause of fire, land cover type and location of ignition in terms of administrative division of Portugal.

The database was screened for inconsistencies, such as records with null values of burned area, with the same date, time and spatial location, negative durations, missing and/or suspicious information about area and duration. Pereira et al. (2011) provide a full description of these inconsistencies and a detailed description of the corrected PRFD.

\subsection{Fire danger rating}

Fire danger is based on the so-called Daily Severity Rating (DSR) that is part of the the Canadian Forest Fire Weather Index System (CFFWIS). This system has been in operational use in Portugal since 1998 by the national weather service (Instituto Português do Mar e da Atmosfera, IPMA) (Pereira et al., 2013). CFFWIS involves six different components based on fuel moisture and wind; three fuel based mechanisms and three fire behaviour indices that are based on daily fields of temperature, relative humidity, wind speed and 24-hour cumulated precipitation at 12 UTC (Van Wagner, 1987). DSR is derived from the Fire Weather Index (FWI), the last component of CFFWIS by means of a simple power function and may be viewed as a numeric rate of the difficulty of controlling fires. DSR was specifically designed for averaging or accumulation in time or space and is currently used in the official annual reports of fire activity in Portugal.

\subsection{Statistic model of burned area}

Pereira et al. (2013) have shown that the decimal logarithm of $B A$ recorded in July and August over Portugal in the 32-year period 1980-2011 follows a normal distribution. Normal models were accordingly fitted to the recorded sample of $x=\log _{10}(B A)$. Estimates of the mean $(\mu)$ and standard deviation $(\sigma)$ were obtained by maximum likelihood (Wilks, 2006). 
Following DaCamara et al. (2014) the fitted model, hereafter referred to as null model of fire danger, may be used to estimate baseline danger $D_{b o}$ which is defined as the probability that a prescribed threshold $x_{0}$ of $\log _{10}(B A)$ is exceeded:

$$
D_{b o}=D_{b}\left(x_{0}\right)=1-N_{x}\left(x_{0} \mid \mu, \sigma\right)
$$

Conversely, the excess threshold associated to a prescribed level of baseline danger $D_{b o}$ may be estimated by inverting the previous equation:

$$
x_{0}=x\left(D_{b 0}\right)=N^{-1}\left(1-D_{b 0}\right)
$$

Normal models for $\log _{10}(B A)$ may be improved by incorporating meteorological covariates that numerically rates fire danger at different temporal and spatial scales. Let $\psi$ and $\chi$ be two such meteorological covariates and let us assume a linear dependence of the mean $(\mu)$ of the normal distribution on the covariates:

$$
\mu=a \times \psi+b \times \chi+c
$$

Estimates of coefficients $a, b, c$ and of $\sigma$ are again obtained by maximum likelihood. Performance of the new alternate model, hereafter referred to as the meteorological model of fire danger, is compared against the null model (i.e. the normal without covariates) by using the standard likelihood ratio test.

The meteorological model allows estimating the "climate + weather" danger $D_{c+w}$ which is defined as the probability that a certain threshold, $x_{0}$, of $\log _{10}(B A)$ is exceeded given two values of $\psi$ and $\chi$ :

$$
D_{c+w}\left(x_{0}, \psi, \chi \mid a, b, c, \sigma\right)=1-\mathrm{N}\left(x_{0} \mid a \times \psi+b \times \chi+c, \sigma\right)
$$

\section{Results}

\subsection{Null model}

A normal model was fitted to the 32-year sample (1980-2011) of cumulated BA in August (Figure 3). Obtained maximum likelihood estimates of mean and standard deviation are $\mu=4.07$ and $\sigma=0.55$ and the probability associated to the Anderson-Darling statistics is 0.66 , meaning that the null hypothesis that the sample is normally distributed cannot be rejected at the level of $5 \%$.

Two different thresholds were chosen, one to discriminate between severe and non-severe years and the other one to discriminate between moderate and weak years. The first threshold, $\mathrm{x}_{20}$, is associated to a baseline danger of $20 \%$, whereas the second one, $\mathrm{x}_{80}$, is associated to a baseline danger of $80 \%$. Values were estimating using Eq. (2), leading to $\mathrm{x}_{20}=4.6$ and $\mathrm{x}_{80}=3.6$ that correspond to values of BA of 34,295 ha and 4,025 ha, respectively. These thresholds were then used to classify each year into one of three categories, namely severe, moderate and weak; as shown in Figure 3, severe (weak) years are those such that $x>x_{20}\left(x<x_{80}\right)$, the remaining ones being classified as moderate. 


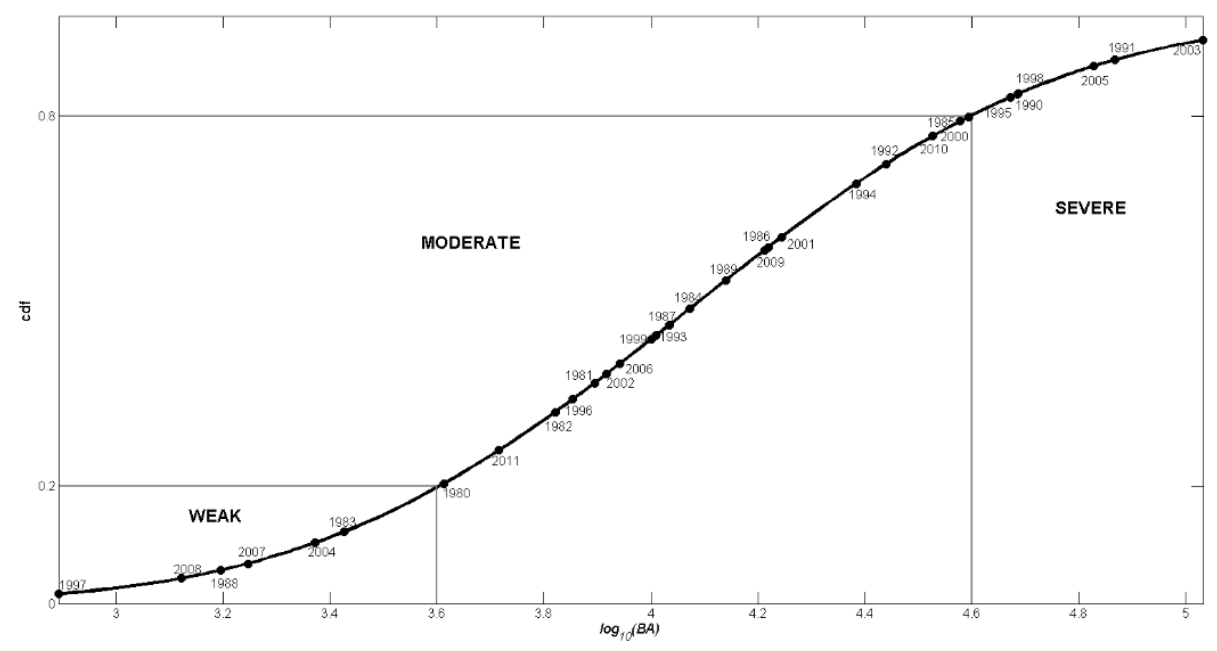

Figure 3. Cumulative distribution function of the baseline model. Dashed lines indicate thresholds $x_{20}$ and $x_{80}$ associated to baseline risks of $20 \%$ and $80 \%$, which are used to stratify the 36-year sample into classes of weak, moderate and severe years represented by black squares, open triangles and black circles, respectively.

\subsection{Meteorological factors}

Pereira et al. (2005) have shown that the inter-annual variability of burned area in Portugal during the fire season is conditioned by two main meteorological factors that work at different temporal and spatial scales; i) a top-down factor (referred to as the "climate anomaly"), linked to long dry periods with absence of precipitation in late spring and early summer, which induce heat and water stress in the vegetation and ii) a bottom-up factor (referred to as the "weather anomaly"), related to the occurrence of very intense dry spells in days of extreme synoptic situations.

\section{Top-down factor}

Pereira et al (2013) have recently shown that the "climate anomaly" may be quantified using cumulated values of DSR in the pre-fire season (May and June). As shown in Figure 4 (left panel) severe (weak) years tend to present larger (smaller) values of cumulated DSR than the overall median. As discussed in Pereira et al (2013) the larger values of cumulated DSR in the case of severe years is associated to systematic increases in temperature and decreases in precipitation that take place in the pre-fire season and drive biomass to high levels of heat and water stress, making them prone to trigger large wildfires in case of favourable meteorological conditions in the fire season, which are very likely to occur in hot and dry summers. The opposite situation is observed in the case of weak years, where the tendency towards lower values of DSR than the overall median is associated to decreases in temperature and to increases in precipitation that make vegetation much less prone to trigger large wildfires, even in case of favourable meteorological conditions.

The role played by the "climatological background" associated to the prevailing meteorological conditions during the pre-fire season was therefore characterized by means of cumulated values of DSR since April 1 till June 15 / June 30 / July 15 / July 31, depending on the model to be developed. Values of cumulated DSR will be hereafter referred to as the top-down factor and denoted $D S R_{t d}$, Choice of the term top-down is because $D S R_{t d}$ has a time scale longer than the monthly scale of BA. 


\section{Bottom-up factor}

Trigo et al. (2006) and Amraoui et al. (2013) pointed out the crucial role played by heatwaves associated to extreme synoptic situations in the onset and spreading of extreme fire events. In the case of Portugal such extreme synoptic situations favour the advection of very hot and dry air throughout central Iberia (Pereira, et al., 2005) and are usually associated to sequences of days, within the month, characterized by large positive departures of DSR from the respective daily climatology, i.e. days with values of anomaly $A_{d}$ defined as:

$$
A_{d}=D S R_{d}-\overline{D S R_{d}}
$$

where $D S R_{d}$ and $\overline{D S R_{d}}$ denote the daily value of DSR for August on day d of a given year and the respective daily climatological mean performed over the 32-year period. The role played by "daily weather" associated to extreme synoptic conditions that favour or prevent fire onset and spreading within a given month was characterized by hereafter referred to bottom-up factor, $D S R_{b u}$, defined by the square root of the mean of squared anomalies performed over the days where $D S R>\overline{D S R_{d}}$, hereafter referred to as:

$$
D S R_{b u}=\sqrt{\frac{\sum_{d=1}^{31} H\left[A_{d}\right]\left(A_{d}\right)^{2}}{\sum_{d=1}^{31} H\left[A_{d}\right]}}
$$

where $\mathrm{H}[\mathrm{x}]$ is the Heaviside step function whose value is zero for negative argument and one for positive argument. As opposed to $D S R_{t d}$, the bottom-up factor $D S R_{b u}$ reflects the effects associated to daily time scales that are smaller than the monthly scale of BA. As shown in Figure 4 (right panel), severe (weak) years tend to present larger (smaller) values of $D S R_{b u}$ than the overall median.

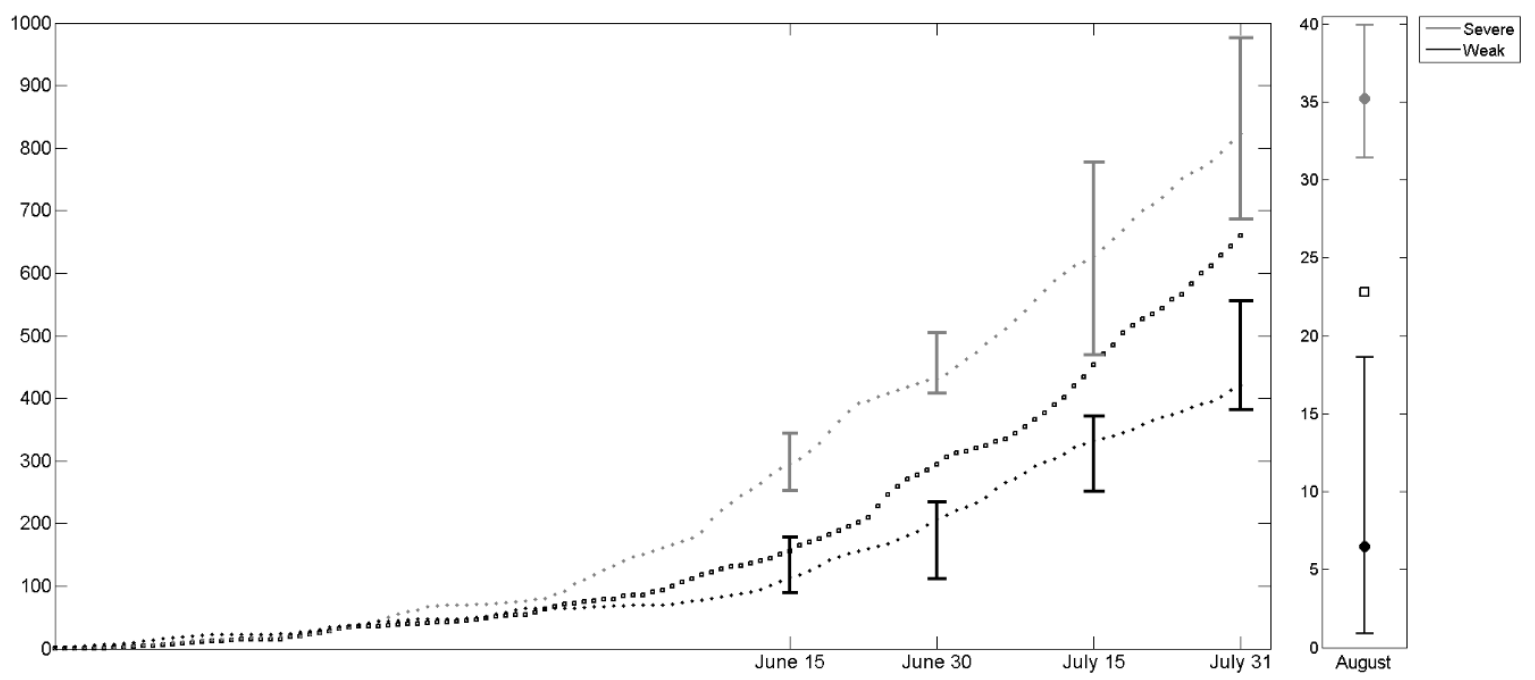

Figure 4. Left panel: daily values from April 1 to July 31 of median values of DSRtd for the entire period (1980-2011) (large black circle) and for the subsample of severe years (small light grey circles) and of weak years (small dark grey circles); whiskers in the two subsamples delimit the first and third quartiles of DSRtd. Right panel: as in the left panel but for the distribution of DSR $b u$ in August. 


\section{Meteorological model}

Values of $D S R_{t d}$ and $D S R_{b u}$ were used as covariates of the normal model of $\mathrm{x}$, assuming a linear dependence in $\mu$ as in Equation (3) with $\psi=D S R_{t d}$ and $\chi=D S R_{b u \text {. }}$ Obtained maximum likelihood estimates are $\mathrm{a}=0.09, \mathrm{~b}=0.02, \mathrm{c}=3.07$ and $\sigma=0.55$ and the p-value of the likelihood ratio test is 0.0001 , indicaing that adding the two covariates results in an improvement in the model that is statistically significant at the $0.01 \%$ level.

\subsection{Model of fire severity \\ Model in diagnostic mode}

Following DaCamara et al. (2014), the impact of the top-down and bottom up factor on burned area was statistically characterized by defining meteorological fire danger $M F D$, according to the following procedure:

1. A given threshold of baseline danger, $D_{\mathrm{b} 0}$, is fixed over the entire study area and the corresponding threshold $x_{0}$ is computed using Eq. (2);

2. For each year, the meteorological model is used to estimate the "climate + weather" danger, $D_{\mathrm{c}+\mathrm{w}}$, using Eq. (4) with threshold $x_{0}$ as defined in the previous step and the values of $D S R_{t d}$ and $D S R_{b u}$;

3. Meteorological fire danger, $M F D$, is finally defined as the ratio between "climate + weather" danger, $D_{\mathrm{c}+\mathrm{w}}$ and prescribed baseline danger $D_{\mathrm{b} 0}$ :

$$
M F D=\frac{D_{c+w}}{D_{b 0}}
$$

The usefulness of meteorological fire danger may be assessed by making a model of fire severity that assigns levels of severity (low, medium, high) to a given year based on values of $D_{m d}$ associated to values of baseline danger $D_{b 0}$ of $20 \%$ and $80 \%$. The procedure is shown in Figure 5, where values, $M F D_{20}\left(M F D_{80}\right)$ of meteorological fire danger associated to a baseline danger $D_{b 0}$ of $20 \%(80 \%)$ are shown in the upper (lower) panel, using values of top-down factor $D S R_{t d}$ accumulated until July 31. The severity level of a given year is classified as high (not-high) if $M F D_{20} \geq 1.5\left(M F D_{20}<1.5\right)$; a nothigh year is then classified as a low (medium) level year if $M F D_{80} \leq 0.76\left(M F D_{80}>0.76\right)$.

Results obtained are shown in Tables 1 and 2. There is a very good agreement between categories based on observed values of BA (weak, moderate and severe) and modelled levels of fire severity (low, medium, high); 25 (78\%) were correctly classified out of 32 cases; all the remaining years were nevertheless attributed the immediate level and 2007 is the only misclassified extreme year (i.e. a weak year classified as one of medium level). 

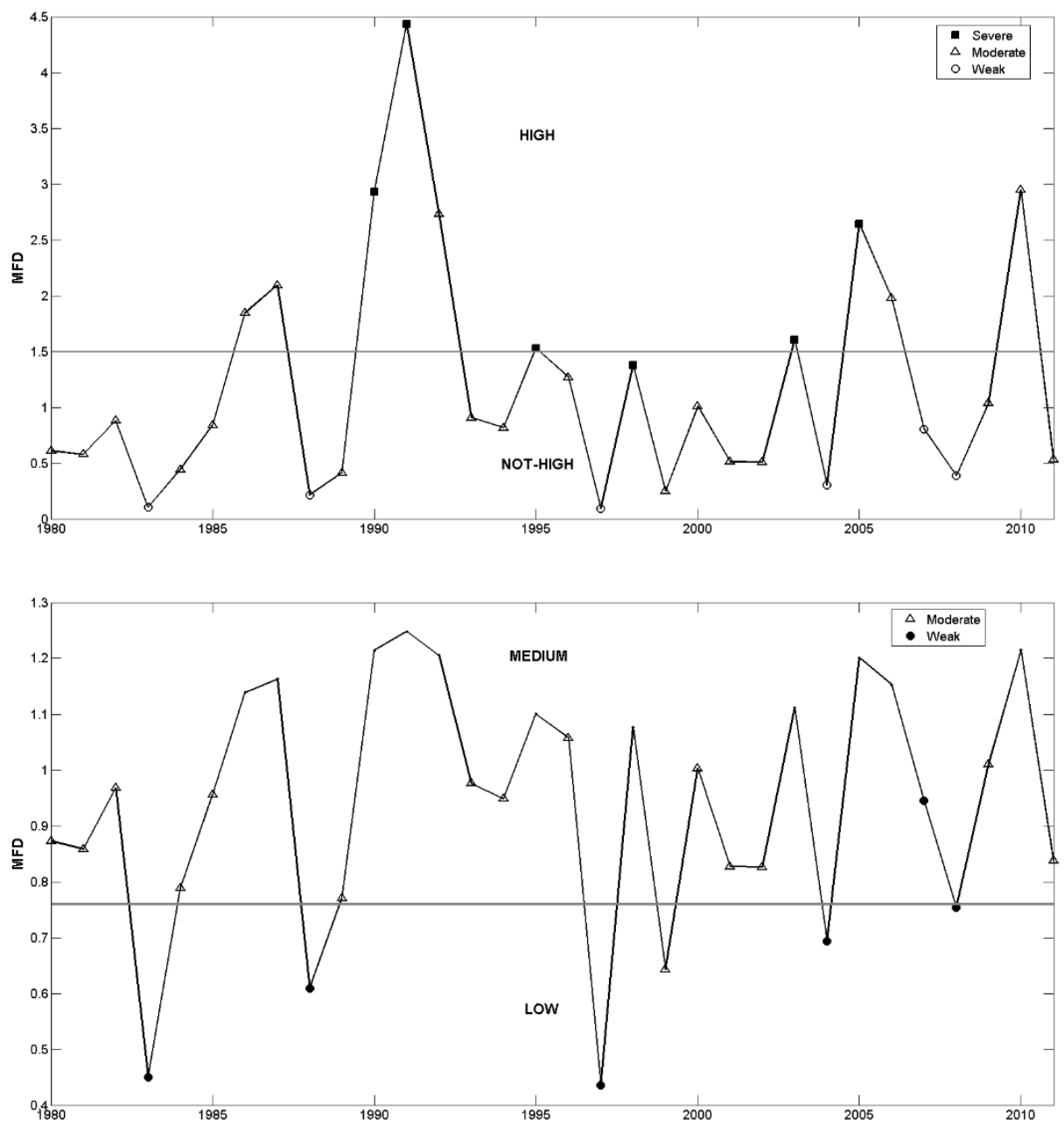

Figure 5. Time series of Meteorological Fire Danger (MFD) associated to values of baseline danger $D_{b 0}$ of $20 \%$ (upper panel) and $80 \%$ (lower panel). The horizontal dotted lines define the thresholds of 1.50 (upper panel) and of 0.76 (lower pane) that are used to classify a given year as high/not high (upper panel) and as low/medium level (lower panel). Squares, triangles and circles indicate years according to the categories of severe, moderate and weak according to the observed value of BA (Figure 3).

Table 1. Quality assessment of the fire danger model; years correctly classified by the model are printed in bold.

\begin{tabular}{|c|c|c|}
\hline \multicolumn{2}{|c|}{ Modelled } & Years \\
\hline \multicolumn{2}{|l|}{ High } & 19861987199019911992199519982003200520062010 \\
\hline \multirow{2}{*}{ Not high } & Medium & 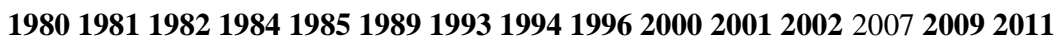 \\
\hline & Low & 198319881997199920042008 \\
\hline
\end{tabular}

Table 2. Contingency tables of observed categories of burned severity (Figure 3) versus modelled levels of severity.

\begin{tabular}{|c|c|c|c|c|}
\hline & \multicolumn{3}{|c|}{$\begin{array}{l}\text { Modelled levels of } \\
\text { Severity }\end{array}$} \\
\hline & & High & Medium & Low \\
\hline \multirow{3}{*}{ 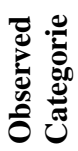 } & Severe & 6 & 0 & 0 \\
\hline & Moderate & 5 & 14 & 1 \\
\hline & Weak & 0 & 1 & 5 \\
\hline
\end{tabular}




\section{Model in prediction mode}

The developed model of fire severity may be used in prediction mode at different stages of the year, namely. June 15, June 30, July 15 and July 31 when only the corresponding value of top-down danger $D_{t d}$ is known. The procedure is as follows:

1. Maximum likelihood estimates of parameters $\mathrm{a}, \mathrm{b}$ and $\mathrm{c}$ of meteorological models are estimated that use as covariates $D_{b u}$ in August and $D_{t d}$ accumulated until each stage (Table 3):

2. Value of $D_{c+w}=0.3$ for the high severity threshold is obtained by inverting Eq. (7) using $M F D_{20}=1.50$ and $D_{b 0}=20 \%$. In a similar way value of $D_{c+w}=0.6$ for low severity is obtained using $M F D_{80}=0.76$ and $D_{b 0}=80 \%$.

3. Value of $\mu^{+}=4.25$ is obtained by inverting Eq. (4) using $D_{c+w}=0.3, x_{20}=4.6$ and $\sigma=0.55$. Value of $\mu^{-}=3.76$ is similarly obtained using $D_{c+w}=0.6, x_{80}=3.6$ and $\sigma=0.55$.

4. Values of $D S R_{b u}^{+}$and $D S R_{b u}^{-}$are obtained by inverting Eq. (3) and using observed value of $D S R_{t d}$ : and appropriate coefficients a, b and c (Table 3):

$$
\begin{aligned}
& D S R_{b u}^{+}=\frac{\mu^{+}-a \times D S R_{t d}-c}{b} \\
& D S R_{b u}^{-}=\frac{\mu^{-}-a \times D S R_{t d}-c}{b}
\end{aligned}
$$

5. The severity of the year is classified as "not high" if $\operatorname{Prob}\left\{D S R_{b u}>D S R_{b u}^{+}\right\}<20 \%$; in a similar way the severity is classified as "not low" if $\operatorname{Prob}\left\{D S R_{b u}<D S R_{b u}^{-}\right\}<20 \%$. When none of the two conditions is satisfied the level of severity is considered unknown. Probabilities are empirically estimated by fitting a normal distribution to the 32-year sample of observed values of $D S R_{b u}(1980-2011)$.

Table 3. Maximum likelihood estimates of parameters $a, b$ and $c$ for meteorological models of fire danger using values of $\mathrm{DSR}_{\mathrm{td}}$ observed at four different stages of the year.

$\begin{array}{lcccc} & \text { June 15 } & \text { June 30 } & \text { July 15 } & \text { July 31 } \\ \text { a } & 0.05 & 0.09 & 0.08 & 0.09 \\ \text { b } & 0.02 & 0.02 & 0.02 & 0.02 \\ \text { c } & 3.39 & 3.25 & 3.19 & 3.07\end{array}$

Obtained results are shown in Table 4 and it may be noted that models for June 15, June 30, July 15 and July 30 correctly anticipate years with levels of severity of "not low" in 17 out of 19 classifiable cases, in 18 out of 19, in 18 out of 19 and in 20 out of 21 years, respectively; the models are also able to correctly anticipate years with levels of severity of "not high" in 1 out of 2 classifiable cases, in 9 out of 10, in 8 out of 9 and in 10 out of 11 years, respectively. It is apparent that years with levels of "not low" may be correctly anticipated at an earlier stage of the year than those with levels of "not high"; this is especially true when comparing severe years that are never classified as "unknown" by the model with the case of weak years where the same only occurs for the model of July 31 . Finally it is worth noting that all model (since June 15) are able to correctly classify as "not low" all but one of the severe years, the only exception (1998) being erroneously classified as "not severe" by models at all stages of the year. A possible explanation is an anomalous accumulation of biomass, given the fact that 1997 was by far the year with lowest burned area. Predictions seem less robust for weak years, all but one year (2004) being correctly classified as "not high" at the last stage (July 31); again the exception is incorrectly classified at all stages but it is worth noting that large fires occurred in the first days of September (which if included would turn 2004 into a moderate year). 
Table 4. Results from model of fire severity used in prognostic mode at four different stages of the year. Symbols $\checkmark$, $\star x$ and ? identify correctly classified, incorrectly classified and unknown years.

\begin{tabular}{|c|c|c|c|c|c|c|c|c|c|c|}
\hline \multirow[b]{2}{*}{ Classification } & \multirow[b]{2}{*}{ rank } & \multirow[b]{2}{*}{ year } & \multicolumn{2}{|c|}{ June 15} & \multicolumn{2}{|c|}{ June 30} & \multicolumn{2}{|c|}{ July 15} & \multicolumn{2}{|c|}{ July 31} \\
\hline & & & Not-high & Not-low & Not-high & Not-low & Not-high & Not-low & Not-high & Not-low \\
\hline \multirow{6}{*}{ Severe } & 1 & 2003 & & $\checkmark$ & & $\checkmark$ & & $\checkmark$ & & $\checkmark$ \\
\hline & 2 & 1991 & & $\checkmark$ & & $\checkmark$ & & $\checkmark$ & & $\checkmark$ \\
\hline & 3 & 2005 & & $\checkmark$ & & $\checkmark$ & & $\checkmark$ & & $\checkmark$ \\
\hline & 4 & 1998 & $x$ & & $x$ & & $x$ & & $x$ & \\
\hline & 5 & 1990 & & $\checkmark$ & & $\checkmark$ & & $\checkmark$ & & $\checkmark$ \\
\hline & 6 & 1995 & & $\checkmark$ & & $\checkmark$ & & $\checkmark$ & & $\checkmark$ \\
\hline \multirow{20}{*}{ Moderate } & 7 & 1985 & $?$ & $?$ & $\sqrt{ }$ & & $\checkmark$ & & $\sqrt{ }$ & \\
\hline & 8 & 2000 & $?$ & $?$ & & $\checkmark$ & & $\checkmark$ & & $\checkmark$ \\
\hline & 9 & 2010 & & $\checkmark$ & $\checkmark$ & & $?$ & $?$ & & $\checkmark$ \\
\hline & 10 & 1992 & & $\checkmark$ & & $\checkmark$ & & $\checkmark$ & & $\checkmark$ \\
\hline & 11 & 1994 & & $\checkmark$ & & $\checkmark$ & & $\checkmark$ & & $\checkmark$ \\
\hline & 12 & 2001 & & $\checkmark$ & & $\checkmark$ & & $\checkmark$ & & $\checkmark$ \\
\hline & 13 & 1986 & & $\checkmark$ & & $\checkmark$ & & $\checkmark$ & & $\checkmark$ \\
\hline & 14 & 2009 & & $\checkmark$ & & $\checkmark$ & & $\checkmark$ & & $\checkmark$ \\
\hline & 15 & 1989 & $?$ & $?$ & $\checkmark$ & & $\checkmark$ & & $\checkmark$ & \\
\hline & 16 & 1984 & $\checkmark$ & & $\checkmark$ & & $\checkmark$ & & $\checkmark$ & \\
\hline & 17 & 1987 & & $\checkmark$ & & $\checkmark$ & $?$ & $?$ & $\checkmark$ & \\
\hline & 18 & 1993 & $?$ & $?$ & $\checkmark$ & & $\checkmark$ & & $\checkmark$ & \\
\hline & 19 & 1999 & & $\checkmark$ & & $\checkmark$ & & $\checkmark$ & & $\checkmark$ \\
\hline & 20 & 2006 & & $\checkmark$ & & $\checkmark$ & & $\checkmark$ & & $\checkmark$ \\
\hline & 21 & 2002 & & $\checkmark$ & & $\checkmark$ & & $\checkmark$ & & $\checkmark$ \\
\hline & 22 & 1981 & $?$ & $?$ & & $\checkmark$ & & $\checkmark$ & & $\checkmark$ \\
\hline & 23 & 1996 & & $\checkmark$ & & $\checkmark$ & & $\checkmark$ & & $\checkmark$ \\
\hline & 24 & 1982 & & $\checkmark$ & & $\checkmark$ & & $\checkmark$ & & $\checkmark$ \\
\hline & 25 & 2011 & $?$ & $?$ & $?$ & $?$ & & $\checkmark$ & & $\checkmark$ \\
\hline & 26 & 1980 & $?$ & $?$ & $\checkmark$ & & $?$ & $?$ & & $\checkmark$ \\
\hline \multirow{6}{*}{ Weak } & 27 & 1983 & $?$ & $?$ & $?$ & $?$ & $\checkmark$ & & $\checkmark$ & \\
\hline & 28 & 2004 & & $x$ & & $x$ & & $x$ & & $x$ \\
\hline & 29 & 2007 & $?$ & $?$ & $\checkmark$ & & $\checkmark$ & & $\checkmark$ & \\
\hline & 30 & 1988 & $?$ & $?$ & $\checkmark$ & & $\checkmark$ & & $\checkmark$ & \\
\hline & 31 & 2008 & $?$ & $?$ & $\checkmark$ & & $?$ & $?$ & $\checkmark$ & \\
\hline & 32 & 1997 & & $x$ & $?$ & $?$ & $\checkmark$ & & $\checkmark$ & \\
\hline
\end{tabular}

\section{Conclusions}

A study was performed aiming to assess the role of meteorological factors on the inter-annual variability of burned area over a region of Central Portugal. The study covers a 32-year period that extends from 1980 to 2011 . The study region is dominated by forest, the predominant species being maritime pine and eucalyptus. The large fractions of the forested area and the high percentages of tree species that are extremely flammable in summer explain the fact that, although occupying only $18 \%$ of the territory of Portugal, the chosen study area is responsible for $43 \%$ of the burned area in August during the study period. 
A normal distribution model was fitted to the 32-year sample of decimal logarithms of monthly burned area. This model was then improved by introducing as covariates two different measures of prevailing meteorological conditions as derived from Daily Severity Rate (DSR), an indicator of meteorological fire danger; a top-down factor, $D S R_{t d}$, which consists of cumulated values of monthly means of DSR from April 1 to July 31 and a bottom up factor, $D S R_{b u}$, defined as the square root of the mean of the squared daily deviations of DSR in August from daily climatology, the average being performed only over days of positive deviation.

The two models, the one without and the one with meteorological covariates, allow estimating baseline and climate+weather fire danger, both defined as the probability that the monthly burned area exceeds a given threshold. These two quantities allow defining meteorological fire danger, based on which a probabilistic model of fire severity is built that assigns levels of severity to a given year. This model may be used in either diagnostic or prognostic modes. When used in diagnostic mode, 25 (78\%) out of 32 cases were correctly classified. When used in prognostic mode, at four different stages of the year (June 15, June 30, July 15 and July 31), the very large majority of years with levels of severity classified as "not low" (17 out of 19 classifiable cases, 18 out of 19, 18 out of 19 and 20 out of 21 years, respectively) were correctly anticipated. Good results were also obtained for years with levels of severity classified as "not high" ( 1 out of 2 classifiable cases, 9 out of 10, 8 out of 9 and in 10 out of 11 years, respectively).

Results from the present study put into perspective the key roles played by meteorological factors associated to different spatial and temporal scales on the occurrence of fire seasons characterized by very high or very low fire activity. This information may be of use to forest managers when organizing fire preventing measures and firefighting capacity and when allocating resources for both. It may be also useful when developing an on-line alarm system to predict the event of extreme fires since such a system depends on constructing a sound model that links the fire size process to the multivariate exploratory variables.

\section{Acknowledgements}

This study was performed within the framework of the EUMETSAT LSA SAF project. The LSA SAF has also supported research grants of Sílvia A. Nunes, Sofia L. Ermida and Teresa J. Calado. The Portuguese Science Foundation (FCT) has supported the research work by K. F. Turkman (projects PEst-OE/MAT/UI0006/2011and PTDC/MAT/118335/2010).

\section{References}

Aldersley A, Murray SJ, Cornell SE (2011). Global and regional analysis of climate and human drivers of wildfire. Science of The Total Environment 409, 18, 3472-3481. doi: 10.1016/j.scitotenv.2011.05.032

Amraoui M, Liberato MLR., Calado TJ, DaCamara CC, Coelho LP, Trigo RM, Gouveia CM (2013). Fire activity over Mediterranean Europe based on information from Meteosat-8. Forest Ecology and Management 294, 62-75. doi: 10.1016/j.foreco.2012.08.032

Costa L, Thonicke K, Poulter B, Badeck F (2011). Sensitivity of Portuguese Forest Fires to Climatic, Human, and Landscape Variables: Subnational Differences between Fire Drivers in Extreme Fire Years and Decadal Averages. Regional Environmental Change 11, 543-51. doi: 10.1007/s10113010-0169-6

DaCamara CC, Calado TJ, Ermida SL, Trigo IF, Amraoui M, Turkman KF, (2014). Calibration of the Fire Weather Index over Mediterranean Europe based on fire activity retrieved from MSG satellite imagery. International Journal of Wildland Fire, doi: 10.1071/WF13157

Dale VH, Joyce LA, McNulty S, Neilson RP, Ayres MP, Flannigan MD, Hanson PJ, Irland LC, Lugo AE, Peterson CJ, Simberloff D, Swanson FJ, Stocks BJ, Wotton BM (2001). Climate change and 
forest disturbances. BioScience 51, 723-734. doi: 10.1641/00063568(2001)051[0723:CCAFD]2.0.CO;2

Flannigan M, Cantin AS, de Groot WJ, Wotton M, Newbery A, Gowman LM (2013). Global wildland fire season severity in the 21st century. Forest Ecology and Management 294, 54-61. doi: 10.1016/j.foreco.2012.10.022

Ganteaume A, Camia A, Jappiot M, San-Miguel-Ayanz J, Long-Fournel M, Lampin C (2012). A review of the main driving factors of forest fire ignition over Europe. Environmental Management 51, 651-662. doi: 10.1007/s00267-012-9961-z

Lavorel S, Flannigan MD, Lambin EF, Scholes MC (2007). Vulnerability of land systems to fire: Interactions among human, climate, the atmosphere, and ecosystems. Mitigation and Adaptation Strategies for Global Change 12, 33-53. doi: 10.1007/s11027-006-9046-5

Liu Y, Stanturf J, Goodrick S (2010). Trends in global wildfire potential in a changing climate. Forest Ecology and Management 259, 658-697. doi: 10.1016/j.foreco.2009.09.002

Mori AS, Johnson EA (2013). Assessing possible shifts in wildfire regimes under a changing climate in mountains landscapes. Forest Ecology and Management 310, 875-886. doi: 10.1016/j.foreco.2013.09.036

Núñes-Regueira L., Añón J. A. R., Castiñeiras J. P. (1996). Calorific values and flammability of forest species in Galicia. Coastal and hillside zones. Bioresource Technology 57, 283-289. doi: 10.1016/S0960-8524(96)00083-1

Pausas JG, Vallejo V R (1999). The role of fire in European Mediterranean ecosystems. In "Remote sensing of large wildfires in the European Mediterranean basin”. (Chuvieco, E.) pp. 3-16. (Springer, Berlin). doi: 10.1007/978-3-642-60164-4_2

Pereira MG, Trigo RM, DaCamara CC, Pereira JMC, Leire SM (2005). Synoptic patterns associated with large summer forest fires in Portugal. Agricultural and Forest Meteorology 129, 11-25. doi: 10.1016/j.agrformet.2004.12.007

Pereira MG, Malamud BD, Trigo RM, Alves PI (2011). The history and characteristics of the 19802005 Portuguese rural fire database. Natural Hazards and Earth System Sciences 11, 3343-3358. doi: 10.5194/nhess-11-3343-2011

Pereira MG, Calado TJ, DaCamara CC, Calheiros T (2013). Effects of regional climate change on rural fires in Portugal. Climate Research 57, 187-200. doi: 10.3354/cr01176

San-Miguel-Ayanz J, Carlson JD, Alexander M, Tolhurst K, Morgan G, Sneeuwjagt R, Dudley M (2003). Current Methods to Assess Fire Danger Potential. In "Wildland Fire Danger Estimation and Mapping". (Chuvieco, E.) pp. 20-61. (World Scientific Publishing, Singapore)

San-Miguel-Ayanz J, Moreno JM, Camia A (2013). Analysis of large fires in Mediterranean landscapes: Lessons learned and perspectives. Forest Ecology and Management 294, 11-22. doi: 10.1016/j.foreco.2012.10.050

Trigo RM, Pereira JMC, Pereira MG, Mota B, Calado TJ, DaCamara CC, Santo FE (2006). Atmospheric conditions associated with the exceptional fire season of 2003 in Portugal. International Journal of Climatology 26, 13, 1741-1757. doi: 10.1002/joc.1333

Trigo RM, Sousa PM, Pereira MG, Rasilla D, Gouveia CM (2013). Modelling wildfire activity in Iberia with different atmospheric circulation weather types. International Journal of Climatology 294, 54-61. doi: 10.1016/j.foreco.2012.10.022

Van Wagner CE, 1987. Development and structure of the Canadian Forest Fire Weather Index System. Canadian Forestry Service, Forestry Technical Report 33 (Ottawa)

Wilks DS (2006). Parametric Probability Distributions. In "Statistical methods in the atmospheric sciences". (Academic Press) 2nd edition, vol. 91, pp. 111-116

Yongqiang L, Stanturf J, Goodrick S (2010). Trends in global wildfire potential in a changing climate. Forest Ecology and Management 259, 685-697. doi: 10.1016/j.foreco.2009.09.002 